\title{
Comunicação
}

[Communication]

\section{Avaliação da reação em cadeia da polimerase e do isolamento bacteriológico convencional na detecção de Salmonella Dublin em amostras de fezes de bezerros infectados experimentalmente}

\section{[Evaluation of polymerase chain reaction and standard microbiological techniques for detection of Salmonella} Dublin in fecal samples of infected calves]

\author{
D.G. Silva ${ }^{1}$, D.R. Silva ${ }^{2}$, P.R.L. Silva ${ }^{3}$, E.A.S. Cícero ${ }^{2}$, A.L.J. Ferraz ${ }^{2}$, M.V.F. Lemos ${ }^{4}$, J.J. Fagliari ${ }^{4 *}$
}

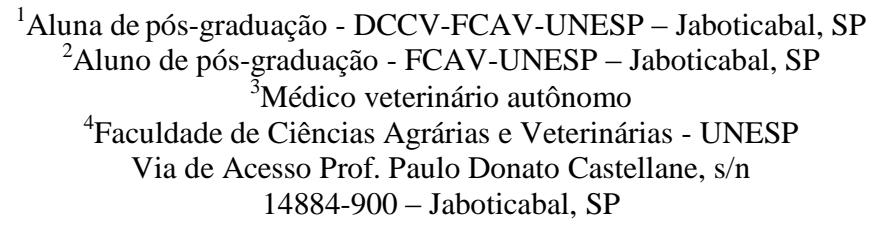

Salmonella é uma bactéria de ocorrência cosmopolita que infecta várias espécies animais, inclusive os seres humanos, sendo incriminada como importante causa de infecções alimentares decorrentes do consumo de carne e leite e seus derivados (Salmonellosis..., 1988). Os sorotipos Salmonella Dublin e Salmonella Typhimurium são os mais frequentemente isolados em bovinos, sendo Salmonella Dublin o sorotipo adaptado à espécie bovina e um dos principais agentes etiológicos de diarreia em bezerros (Santos et al., 2002).

O método de isolamento tradicional de Salmonella baseia-se no cultivo bacteriológico, com a utilização de meios seletivos, seguido de caracterização das colônias suspeitas em testes bioquímicos e sorológicos (Soumet et al., 1999). Porém, sua realização é demorada (quatro a sete dias), podendo ser laboriosa e onerosa quando aplicada em larga escala.

A reação em cadeia da polimerase (PCR) vem se destacando como importante ferramenta no diagnóstico de salmonelose, em termos de rapidez e sensibilidade (Freschi et al., 2005). Entretanto, o maior obstáculo para o uso dessa técnica é a presença de altas concentrações de substâncias inibidoras da PCR em amostras de

Recebido em 16 de novembro de 2009

Aceito em 10 de junho de 2010

*Autor para correspondência (corresponding author)

E-mail: fagliari@fcav.unesp.br fezes, o que limita a utilização direta das fezes como DNA-molde (Feder et al., 2001). O enriquecimento em meio seletivo antes da etapa de extração do DNA tem sido considerado um procedimento promissor para detecção de Salmonella em amostras de fezes, pois, além de ser uma etapa comum ao isolamento microbiológico, permite a multiplicação da bactéria-alvo e, também, dilui células mortas e substâncias inibidoras da PCR (Knutsson et al., 2002).

O objetivo do estudo foi avaliar a eficiência da PCR combinada com enriquecimento em caldo seletivo comparativamente ao isolamento bacteriológico convencional na detecção de Salmonella Dublin em amostras de fezes de bezerros infectados experimentalmente com a bactéria.

Foram analisadas 76 amostras de fezes obtidas por meio de suabes retais de seis bezerros da raça Holandesa, com 10 a 15 dias de idade, infectados experimentalmente com $10^{8}$ unidades formadoras de colônia (UFC) de Salmonella Dublin (registro IOC 3101/03, Fundação Oswaldo Cruz, Manguinhos, RJ), por via oral. As amostras foram colhidas em duplicata, imediatamente antes da inoculação, e em intervalos de doze horas, ao longo de sete dias após a infecção experimental. 
O isolamento de Salmonella Dublin foi realizado por meio de cultura bacteriológica convencional e pela técnica de PCR. No isolamento bacteriológico, as amostras de suabes retais foram inoculadas nos caldos de enriquecimento seletivo selenito cistina (SC) (CM0699, Oxoid) e tetrationato Muller-Kauffman (TKM) (CM 0343, Oxoid) e incubados a $37^{\circ} \mathrm{C}$ durante 24 horas. Após incubação, os caldos foram semeados em placas contendo ágar verde-brilhante modificado (CM0329, Oxoid), com $50 \mu \mathrm{g} / \mathrm{mL}$ de ácido nalidíxico, e incubados a $37^{\circ} \mathrm{C}$ por 24 horas. De cada placa, três colônias sugestivas de bactérias do gênero Salmonella foram inoculadas em tubos contendo ágar tríplice açúcar e ferro (CM0277, Oxoid) e ágar lisina ferro (CM0381, Oxoid). Todas as colônias identificadas presuntivamente como Salmonella foram submetidas ao teste de soroaglutinação em lâmina, com soro polivalente antiantígeno somático $(\mathrm{O})$ e com soro polivalente antiantígeno flagelar $(\mathrm{H})$ de Salmonella.

A partir de alíquotas dos dois caldos de enriquecimento seletivo, foi realizada a extração de DNA para realização de PCR, pela técnica de salting-out (Silva, 2007). Também foi avaliada a sensibilidade da PCR na detecção de Salmonella Dublin com o uso das técnicas de extração de DNA por fervura-centrifugação, fervura-fenol e salting-out nos caldos Rappaport-Vassiliadis, selenito cistina e tetrationato Muller-Kauffmann (Freschi, 2003). A PCR tipo multiplex foi realizada em volume final de $25 \mu \mathrm{L}$, com $5 \mu \mathrm{L}$ de amostra de DNA adicionado a $20 \mu \mathrm{L}$ da mistura de reação contendo $2,0 \mathrm{mM}$ de $\mathrm{MgCl}_{2} ; 70 \mu \mathrm{M}$ de cada deoxinucleotídeo; $0,4 \mu \mathrm{M}$ de cada primer (RE1:5'-CTTGGGAGTAATCTTGCC-3'; RE2:5'-TATACTGCCGTACTGCCT-3'; FC1:5'-TGATCTCTTTAAGACCACTA-3': FC2:5'-ACATCCGTCGCGCCAGTGGC-3'), específicos para os segmentos $r f b E$ e fliC presentes nas cepas de Salmonella pertencentes ao sorogrupo D (Itoh et al., 1997), e 1U de Taq polimerase. A reação foi realizada em termociclador (PTC-100, MJ Research) ajustado para 35 ciclos: $95^{\circ} \mathrm{C}$ por 30 segundos (desnaturação), $\quad 56^{\circ} \mathrm{C}$ durante 30 segundos (pareamento) e $72^{\circ} \mathrm{C}$ por 30 segundos (extensão). A amplificação do DNA também foi realizada nos controles positivos e negativos. Os produtos da PCR foram separados por eletroforese em gel de agarose $1,5 \%$, corados com brometo de etídeo, visualizados e registrados em fotodocumentador (Gel Doc 2000, Bio-Rad). As amostras apresentando fragmentos de $307 \mathrm{e} / \mathrm{ou}$ $225 \mathrm{pb}$ foram consideradas positivas.

Os resultados da detecção de Salmonella Dublin obtidos pelo isolamento bacteriológico convencional e pela PCR foram submetidos à análise estatística, pelo teste do qui-quadrado e pelo índice de concordância Kappa (Zar, 1999).

O isolamento bacteriológico convencional possibilitou a detecção de 44 (57,9\%) e 42 $(55,3 \%)$ amostras positivas para Salmonella Dublin, enquanto a técnica de PCR possibilitou a detecção de $41(53,9 \%)$ e $35(46,1 \%)$ amostras positivas para Salmonella Dublin, ambas com a utilização dos caldos SC e TMK, respectivamente (Fig. 1). O limiar de detecção da PCR pelo método de extração de DNA por salting-out foi de $10^{2} \mathrm{UFC} / \mathrm{mL}$ nos caldo SC e TMK (Tab. 1). Nenhuma das amostras obtidas antes da infecção experimental foi positiva para $S$. Dublin, em ambas as técnicas.

Independentemente do caldo de enriquecimento seletivo utilizado, o isolamento bacteriológico convencional foi superior à PCR na detecção de amostras positivas para Salmonella Dublin a partir de suabes retais $(\mathrm{P}<0,0001)$. A concordância entre o isolamento bacteriológico convencional e a PCR foi considerada moderada $(0,49$ com o uso do caldo SC e 0,45 com o uso do caldo TMK).

A PCR, quando comparada ao isolamento bacteriológico convencional, apresentou sensibilidade e especificidade de 75,0\%, quando associada ao caldo SC (Tab. 2), e sensibilidade de $66,7 \%$ e especificidade de 79,4\%, quando associada ao caldo TMK (Tab. 3). 


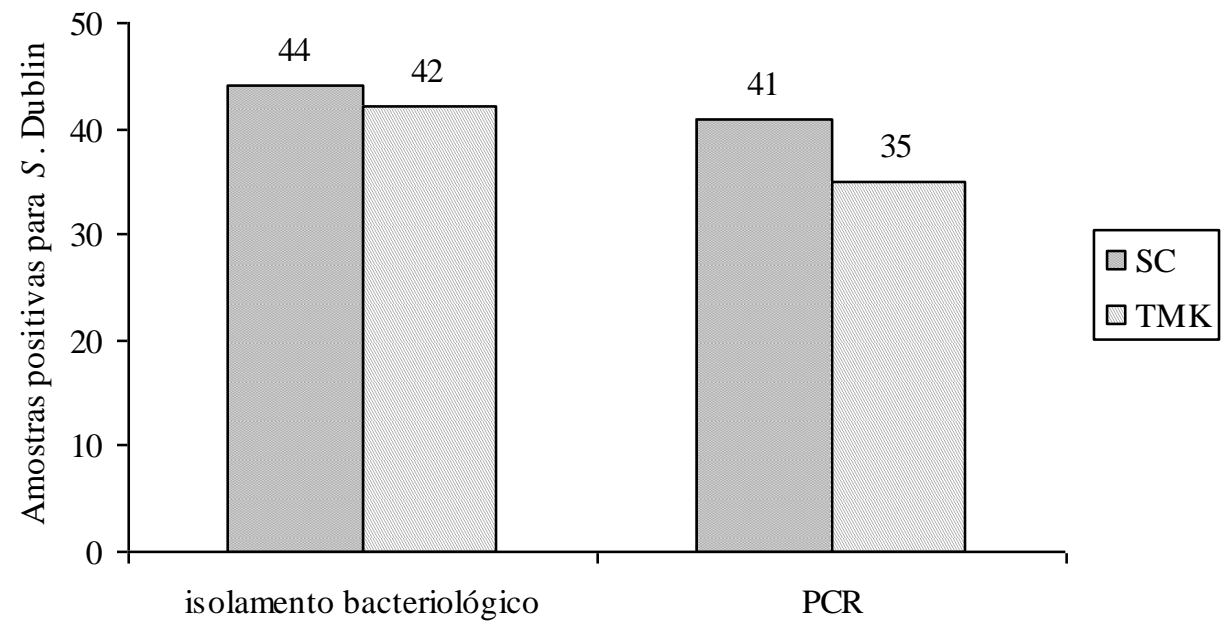

Figura 1. Número de amostras positivas para Salmonella Dublin detectadas em isolamento bacteriológico convencional e em PCR, nos caldos selenito cistina (SC) e tetrationato Muller-Kauffmann (TMK), em amostras de fezes de bezerros infectados experimentalmente com $10^{8}$ UFC de $S$. Dublin.

Tabela 1. Limiar de detecção de cultura pura de Salmonella Dublin (UFC/mL) em PCR utilizando-se diferentes métodos de extração de DNA (fervura-centrifugação, fervura-fenol e salting-out) e diferentes caldos de enriquecimento seletivo (Rappaport-Vassiliadis, selenito cistina e tetrationato MullerKauffmann)

\begin{tabular}{lccc}
\hline \multirow{2}{*}{$\begin{array}{c}\text { Caldos de enriquecimento } \\
\text { seletivo }\end{array}$} & \multicolumn{3}{c}{ Métodos de extração de DNA } \\
\cline { 2 - 4 } & $\begin{array}{c}\text { Fervura- } \\
\text { centrifugação }\end{array}$ & $\begin{array}{c}\text { Fervura- } \\
\text { fenol }\end{array}$ & Salting-out \\
\hline Rappaport-Vassiliadis & $10^{6}$ & $10^{5}$ & $10^{5}$ \\
Selenito cistina & $10^{3}$ & $10^{4}$ & $10^{2}$ \\
Tetrationato Muller-Kauffmann & $10^{7}$ & $10^{8}$ & $10^{2}$ \\
\hline
\end{tabular}

Tabela 2. Resultados comparativos entre o isolamento bacteriológico convencional e a PCR, com a utilização do caldo selenito cistina, na detecção de Salmonella Dublin em fezes de bezerros infectados experimentalmente com a bactéria

\begin{tabular}{cccc}
\hline \multirow{2}{*}{ PCR } & \multicolumn{2}{c}{ Isolamento bacteriológico } & \multirow{2}{*}{ Total } \\
\cline { 2 - 4 } & Positivo & Negativo & 41 \\
Positivo & 33 & 8 & 35 \\
Negativo & 11 & 24 & 76 \\
\hline Total & 44 & 32 &
\end{tabular}

sensibilidade $=75,0 \%$; especificidade $=75,0 \%$; Kappa $=0,49$.

Tabela 3. Resultados comparativos entre o isolamento bacteriológico convencional e a PCR, com a utilização do caldo tetrationato Muller-Kauffmann, na detecção de Salmonella Dublin em fezes de bezerros infectados experimentalmente com a bactéria

\begin{tabular}{cccc}
\hline \multirow{2}{*}{ PCR } & \multicolumn{2}{c}{ Isolamento bacteriológico } & \multirow{2}{*}{ Total } \\
\cline { 2 - 4 } & Positivo & Negativo & 35 \\
Positivo & 28 & 7 & 41 \\
Negativo & 14 & 27 & 76 \\
\hline Total & 42 & 34 &
\end{tabular}

sensibilidade $=66,7 \%$; especificidade $=79,4 \% ;$ Kappa $=0,45$. 
Apesar de a maior parte das pesquisas relatarem que a PCR é superior ao isolamento bacteriológico convencional na detecção de Salmonella em diversos tipos de amostras biológicas (Schrank et al., 2001), os resultados obtidos mostraram melhor desempenho do isolamento bacteriológico.

Em relação à associação da PCR ao caldo de enriquecimento, notou-se que o caldo SC é menos inibidor à PCR do que o caldo TMK. Segundo Stone et al. (1994), o caldo TMK contém sais biliares capazes de interferir negativamente no desempenho da PCR.

A despeito de o isolamento bacteriológico convencional ter apresentado desempenho superior ao da PCR na detecção de amostras positivas para Salmonella Dublin, a PCR foi capaz de detectar amostras positivas não identificadas pelo isolamento bacteriológico, em um menor intervalo de tempo.

Assim, os resultados obtidos indicaram superioridade do isolamento bacteriológico convencional em relação à PCR na detecção de S. Dublin em amostras de fezes de bezerros infectados experimentalmente com a bactéria e que o caldo SC foi a melhor opção de enriquecimento seletivo para ambas as técnicas.

Palavras-chave: bezerro, fezes, Salmonella Dublin, PCR, cultura

\begin{abstract}
The efficiency of the Polymerase Chain Reaction (PCR) combined with selective enrichment broth was compared with the standard microbiological techniques for detection of Salmonella Dublin in fecal samples of 10 to 15-days-old Holstein calves, experimentally infected with $10^{8} \mathrm{CFU}$ of Salmonella Dublin. Seventy-six fecal samples were analyzed using PCR associated with selenite cystine (SC) and Muller-Kauffmann tetrathionate (TMK) broths and standard microbiological techniques. Regardless of the selective enrichment broth used, the standard microbiological techniques were significantly better than PCR in detection of positive samples of Salmonella Dublin. However, the simultaneous use of both techniques provided detection of a larger number of positive samples. The SC broth was the best option as selective enrichment in both techniques.
\end{abstract}

Keywords: calves, feces, Salmonella Dublin, PCR, culture

\section{AGRADECIMENTOS}

Os autores agradecem à FAPESP pela concessão de bolsa e auxílio financeiro e à Fundação Oswaldo Cruz pelo fornecimento da cepa de Salmonella Dublin.

\section{REFERÊNCIAS BIBLIOGRÁFICAS}

FEDER, I.; NIETFELD, J.C.; GALLAND, J. et al. Comparison of cultivation and PCRhybridization for detection of Salmonella in porcine fecal and water samples. J. Clin. Microbiol., v.39, p.2477-2484, 2001.

FRESCHI, C.R. Efeito de diferentes meios de enriquecimento seletivo e técnicas de extração de DNA de amostras de fezes suínas sobre a detecção de Salmonella Typhimurium pela reação em cadeia da polimerase (PCR). 2003. 32f. Dissertação (Mestrado) - Faculdade de Ciências Agrárias e Veterinárias, Universidade Estadual Paulista, Jaboticabal.
FRESCHI, C.R.; CARVALHO, L.F.O.S.; OLIVEIRA, C.J.B. Comparison of DNAextraction methods and selective enrichment broths on the detection of Salmonella Typhimurium in swine feces by polymerase chain reaction (PCR). Braz. J. Microbiol., v.36, p.363-367, 2005.

ITOH, Y.; HIROSE, K.; MYIAKE, M. et al. Amplification of $r f b E$ e $f l i C$ genes by polimerase chain reaction for identification and detection of Salmonella serovar Enteritidis, Dublin and Gallinarum-Pullorum. Microbiol. Immunol., v.41, p.791-794, 1997.

KNUTSSON, R.; LOFSTROM, C.; GRAGE, H. et al. Modeling of 5' nuclease real-time responses of optimization of a high-througput enrichment PCR procedure for Salmonella enterica. J. Clin. Microbiol., v.40, p.52-60, 2002. 
SALMONELLOSIS control: the role of animal product hygiene. Geneva: WHO, 1988. (Technical Report Series, 774).

SANTOS, R.L.; ZHANG, S; TSOLIS, R.M. et al. Morphologic and molecular characterization of Salmonella Typhimurium infection in neonatal calves. Vet. Pathol., v.39, p.200-215, 2002.

SCHRANK I.S.; MORES, M.A.Z.; COSTA, J.C.A. et al. Influence of enrichment media and application of a PCR based method to detect Salmonella in poultry industry products and clinical samples. Vet. Microbiol., v.82, p.45-53, 2001.

SILVA, D.G. Estudo clínico, laboratorial e terapêutico da diarreia experimental em bezerros induzida por Salmonella enterica subespécie enterica sorotipo Dublin. 2007. 153f. Tese (Doutorado) - Faculdade de Ciências Agrárias e Veterinárias, Universidade Estadual Paulista, Jaboticabal.
SOUMET, C.; ERMEL, G.; ROSE, V. et al. Identification by multiplex PCR-based assay of Salmonella Typhimurium and Salmonella Enteritidis strains of environmental swabs of poultry houses. Lett. Appl. Microbiol., v.29, p.1$6,1999$.

STONE, G.G.; OBERST, R.D.; HAYS, M.P. et al. Detection of Salmonella serovars from clinical samples by enrichment broth cultivation-PCR procedure. J. Clin. Microbiol., v.32, p.1742-1749, 1994.

ZAR, J.H. Biostatistical analysis. 4.ed. New Jersey: Prentice Hall, 1999. 663p. 